\title{
Chapter 71 \\ Radical Transparency and Brand Equity as Key Factors for Successful Business Strategy
}

\author{
Elena Veselinova \\ Goce Delčev University of Štip, Macedonia \\ Marija Gogova Samonikov \\ Goce Delčev University of Štip, Macedonia
}

\begin{abstract}
This chapter analyzes the phenomenon of branding and the related process of creating new value, and thus a sustainable competitive advantage through recognition of the concept of radical transparency. The brand equity is a common denominator of all tangible and intangible resources of the company, the amount of its abilities, of any activity indicating a slightly higher value, any attempt to be better and to achieve more. Therefore, in addition the brand equity is elaborated as a source of value for the business. This chapter examines the role of brand equity in providing greater market share, creating entry barriers for new competitors, achieving production and market expansion, providing a price premium, attracting quality workforce, ensuring consumers loyalty and stimulating innovation. For the brand equity to truly provide value it should be more than the company's image or position of the product - the brand should be a unifying force across the company, providing the business with direction and purpose.
\end{abstract}

\section{INTRODUCTION}

This chapter analyzes the phenomenon of branding and the related process of creating new value, and thus a sustainable competitive advantage through recognition of the concept of radical transparency. The brand equity is a common denominator of all tangible and intangible resources of the company, the amount of its abilities, of any activity indicating a slightly higher value, any attempt to be better and to achieve more. Therefore, in addition the brand equity is elaborated as a source of value for the business. Here we examine the role of brand equity in providing greater market share, creating entry barriers for new competitors, achieving production and market expansion, providing a price premium, attracting 
quality workforce, ensuring consumers loyalty and stimulating innovation. For the brand equity to truly provide value it should be more than the company's image or position of the product - the brand should be a unifying force across the company, providing the business with direction and purpose.

Brand strategy is more than marketing. Traditionally, the brand is seen as a tool to achieve marketing goals such as increase in the market share or increased repurchase. Consequently, branding is primarily treated as a marketing discipline. Of course, the brand can play these roles, but the brand strategy is more than marketing. Compiling a successful brand equity and functional brand strategy should ensure that all relevant business activities support the position of the brand and that they are carried out openly, transparently and consistently.

Brand strategy is more than communication. To communicate means "to impart information or ideas." In business, it is the well-known, old-fashioned art of persuasion. This logic applies for brands and often with great success. These are the basics of branding: building an image that resonates with consumers putting in their mind what they should buy. However, the brand strategy is more than a plan for the brand image, building a strong brand requires more than communication. The brand strategy ensures that what the company says is what the company does. This is, precisely, the logic of the new business model.

Brand strategy is more than effectiveness and efficiency. The imperative to ensure profit growth led to an increase in operational efficiency in all areas of business. Of course, any well managed business will force efficiency in all areas of its operations: the elimination of losses is essential to maintain competitiveness, and when times are tough, it may be the only way "to survive." However, the efficiency - to do something good, is not itself a strategy.

Brand strategy is more than effectiveness. Achieving an increase in some specific indicators (measures of the success of the brand) may be an indicator that the strategy is on track, but it is not the primary strategic objective of the business. For example, a promotional campaign can lead to a rise in sales, but also can undermine the long-term competitive position of the company. The brand strategy must place a credible difference over competitors. Such competitive difference (advantage) must be sustainable in the long term. The use of radical transparency provides this advantage. Efficiency and effectiveness, of course, are essential, but they are one of the most useful indicators of short-term performance of companies and rarely indicate something more about the long-term trends. With some military terminology and metaphor, efficiency is about how to win the battle and brand strategy with radical transparency about how to win the war.

Brand strategy is more than positioning. It is always important to gain a sustainable competitive advantage over competitors. This question is often interpreted as positioning: Art in finding "a place in the minds of consumers." The positioning means clearly differentiating the brand from those of the competitors. This can, certainly, easier and better be achieved with a transparent and consistent performance - every day, with each activity. The positioning is a useful way of thinking about branding, so much that positioning and branding have become almost synonymous with each other. Usually, when discussing branding, the focus is on the points of difference - the competitive advantage. However, branding is more than creating a single position.

Brand strategy is business strategy. Each brand strategy should answer the following four questions (Miller and Muir, 2004): 1. Who are the customers? 2. Which products / services are offered? 3. How will it perform against competitors? 4. Which resources and capabilities are required? For example, the general articulation of the brand strategy of Southwest Airlines can be stated as something like this: "We will offer flights to short haul, without waiting, with lower prices for customers who want fast, 
25 more pages are available in the full version of this document, which may be purchased using the "Add to Cart" button on the product's webpage: www.igi-global.com/chapter/radical-transparency-and-brand-equity-as-keyfactors-for-successful-business-strategy/195156?camid=4v1

This title is available in InfoSci-Books, InfoSci-Business and Management, Business, Administration, and Management, Communications, Social Science, and Healthcare, InfoSci-Media and Communications, InfoSci-Social Sciences and Humanities, InfoSci-Select, InfoSci-Select. Recommend this product to your librarian:

www.igi-global.com/e-resources/library-recommendation/?id=1

\section{Related Content}

Immersion and Perceived Value: The Strategic Variables For Commercial Websites

Ahmed Anis Charfi (2014). International Journal of Online Marketing (pp. 17-35).

www.igi-global.com/article/immersion-and-perceived-value/127059?camid=4v1a

Understanding Consumer Recommendation Behavior

Wen-Kuo Chen, Heng-Chiang Huang and Seng-Cho T. Chou (2010). Handbook of Research on Mobile

Marketing Management (pp. 401-416).

www.igi-global.com/chapter/understanding-consumer-recommendation-

behavior/39156?camid $=4 \mathrm{v} 1 \mathrm{a}$

Uncovering Relationships Between Emotional States and Higher-Order Needs: Enhancing Consumer Emotional Experiences in Computer-Mediated Environment

Andrew Pressey, Laura Salciuviene and Stuart Barnes (2013). International Journal of Online Marketing

(pp. 31-46).

www.igi-global.com/article/uncovering-relationships-between-emotional-

states/77331?camid $=4 \mathrm{v} 1 \mathrm{a}$

Effectiveness and Content of Corporate Codes of Ethics as a Model for University Honor Codes Katherine Hyatt (2016). International Journal of Technology and Educational Marketing (pp. 52-69). www.igi-global.com/article/effectiveness-and-content-of-corporate-codes-of-ethics-as-a-modelfor-university-honor-codes/146187?camid=4v1a 